\title{
A demographic description of caregivers in Sapporo Japan : male caregivers are here to stay
}

\author{
Asae OURA ${ }^{1}$, Mitsuru MORI ${ }^{2}$, Hisako IZUMI ${ }^{3}$, Hiroko Yako-SUKETOMO ${ }^{4}$, \\ Masakazu WASHIO ${ }^{5}$, Sotaro HANAI ${ }^{6}$, Misa TAKEGAMI ${ }^{6}$, \\ Makoto WATANABE ${ }^{6}$ and Yoshihiro MIYAMOTO ${ }^{6}$
}

The population of elderly in Japan continues to grow as advances in health care are supporting longer living. In traditional Japanese culture, as people age and become frail, they most often continue to live at home and are cared for by family. However, recently the birth rate in Japan has decreased dramatically, and the nuclear family has become standard. Therefore, caregivers often have to take care of the frail elderly without any help because other relatives live in distant places and are unable to help in caring for the frail elderly. The present study aimed to investigate who the caregivers are and the demographic characteristics of caregivers, including the percentage using home health nursing support for their loved ones. Specific focus was on the characteristics and needs of men providing caregiving. Seventy one dyads of caregiver and patient were examined. Differences were found between caregivers' gender.

Male caregivers were more likely to be older $(\mathrm{p}<0.05)$, to be spouse $(\mathrm{p}<0.05)$, longer duration of caregiving $(p<0.05)$, to have a daughter-in-law who helped from outside $(p<0.05)$, and to use home help service $(\mathrm{p}<0.05)$ than female caregivers. Also, male caregivers were less likely to be children $(\mathrm{p}<0.05)$, to care for older frail elderly $(\mathrm{p}<0.05)$, to have a sister or brother who help from outside $(\mathrm{p}<0.05)$, and to use day care service $(0 \%$ v. s. $21.6 \%)$ than their counterparts.

After "caregiver's age" was adjusted, male caregivers were less likely to care for frail elderly persons who were more than 80 years old $(\mathrm{OR}=0.28,95 \% \mathrm{CI}=(0.08,0.994))$ and were more likely to use home-visit care (home help service) $(\mathrm{OR}=5.72,95 \% \mathrm{CI}=(1.75,18.68))$ than female caregivers. The needs of supporting the at home care of male caregivers may be different from female caregivers.

Key words : family caregivers, frail elderly, male caregivers, Long Term Care Insurance, Japan

\footnotetext{
${ }^{1}$ Department of Public Health, Kochi Medical School

${ }^{2}$ Department of Public Health, Sapporo Medical University School of Medicine

${ }^{3}$ Department of Nursing, Sapporo Medical University School of Health Science,

${ }^{4}$ Medical Support and Partnership Section, Center for Cancer Control and Information Services, National Cancer Center

${ }^{5}$ Faculty of Nursing, St. Mary's College,

${ }^{6}$ Department of Preventive Medicine and Epidemiologic informatics, National Cerebral and Cardiovascular Center $(\mathrm{NCVC})$
} 


\section{Introduction}

After World War II, improvements in public health and advances in medicine have given Japan the longest life expectancy in the world (Ministry of Health, Labour and Welfare, 2011 ; Ministry of Internal Affairs and Communications et al., 2011a). This has led to a dramatic increase in the number of elderly people in Japan, which is now well-documented (Ministry of Health, Labour and Welfare, 2011 ; Ministry of Internal Affairs and Communications et al., 2011a), and a concurrent increase in the number of elderly in need of care (frail elderly). Number of 65 years and over in Japan in 2006 was about 26 million (20.7\%) (Ministry of Internal Affairs and Communications et al., 2011b), and in Sapporo in 2008 was 359,983 (19.1\%) (City of Sapporo, 2011a). In Japan, there was the institution, where an elderly needing care enter, for example Geriatric health services facility (Roken nursing home), and Special nursing home for the elderly (Special nursing home) etc (City of Sapporo, 2011b). Frail elderly have been cared for in the traditional Japanese family system where most Japanese elderly live with their children (Campbell, 1992 ; Ministry of Health, Labour and Welfare, 2011).

The Ministry of Health, Labour and Welfare reported that male caregivers were about $10 \%$ in 1997, but increased to nearly $30 \%$ in 2007 (Tsudome and Saito, 2007). All frail elderly are assessed to see if they qualify for elderly care services according to Government Certified Disability Index (Yokaigodo in Japanese) (Shimizu, 2003). In Sapporo 61,444 elderly persons were authorized regarding Yokaigodo, because their ages were 65 years or over (City of Sapporo, 2011a). Problematic, however, is that the government index looks only at the condition of the patient, and not at who is available, or the capabilities of that person, to care for them at home. As one characteristic of caregiving at-home, we thought the gender differences of caregiver-related care settings and use of these services. We desired to assess if differences existed in the needs of caregivers by gender.

Assessing who caregivers are and how they are managing has generated much attention in nursing research. Arai et al. (2001) found that when caregivers were overwhelmed, this led to depression and earlier discontinuation of care for the family member. Calasanti and King (2007) studied 22 husbands caring for their wives at home. These males used coping stratetgies different from those commonly used by females, including "exerting force," "blocking emotions," and "self medicating" with alcohol. Sandberg and Eriksson (2007), too, found that males caring for their wives needed to "focus on a clear set of goals" to cope. Caregiver burden has been the focus of many funded studies by Dr. Carol Farran. Farran and Keane-Hagerty (2011) give evidence based advice to caregivers on how to keep themselves strong.

\section{Subjects and Methods}

A cross-sectional study was conducted in order to assess male and female caregivers for the frail elderly with periodic nurse service in 2008 , in 7 home-visiting nursing service stations in Sapporo, Japan. Demographic characteristics and use of services, with focus on potential differences by caregiver gender, were studied.

Caregiver-patient dyads were identified through 7 home health agencies in Sapporo, Japan. Written informed consent was obtained. This study was approved by the Ethical Boards of Sapporo Medical University.

The caregivers were asked to complete the following self-administered questionnaires in regards to their health status and caregiving situation in the same manner as in our previous studies (Arai 
et al., 2001 ; Oura et al., 2007 ; Washio et al., 2003) : ( i ) questions regarding the caregiver's health status including the Center for Epidemiologic Studies Depression Scale (CES-D) (Kano, 2003 ; Radloff, 1977) ; (ii) questions regarding demographic variables of the caregivers and their frail elderly ; and, (iii) questions regarding several care variables, such as : the time spent physically caregiving, the time spent attending to the frail elderly, and the duration of caregiving. Information on the frail elderly was also collected from medical records.

\section{Data Analysis}

Statistical analyses were performed using the Statistical Package for Social Science (SPSS). Caregivers were divided into two groups according to the gender of the caregivers. The Chi-square test and the Mann-Whitney U-test were used to compare these groups. A multiple logistic regression analysis was conducted to control for any confounding factors related to male caregivers. The odds ratios (OR) and their 95\% confidence intervals (95\% CI) were calculated for each factor based on the logistic regression coefficient and standard error. For each of the estimations, the OR was adjusted for the caregivers' age. A level of 0.05 was used as the critical level of significance.

\section{Results}

Initially informed consent was received from 86 pairs of caregivers and disabled elderly in October 2008. We excluded 15 pairs of patients aged 64 years or younger and their caregivers, because the main users of the Long-term Care Insurance System (LTC) are aged 65 or older. Thus we analyzed 71 pairs in total. The number of frail elderly included 31 males and 40 females with a mean age ( \pm standard deviation ; SD) of $81.1 \pm 8.0$ years. The number of caregivers included 20 males and
51 females with a mean age $( \pm \mathrm{SD})$ of $65.7 \pm 11.6$ years old. The relationship of those caregivers surveyed included : 15 husbands (21.1\%), 20 wives $(28.2 \%), 4$ sons $(5.6 \%), 23$ daughters $(32.4 \%)$, 8 daughters-in-law $(11.3 \%)$, and 1 son-in-law $(1.4 \%)$.

Table 1 shows a comparison between male and female caregivers; characteristics of caregivers and the frail elderly. Male caregivers were more likely to be older (male : $71.7( \pm 11.6)$ years v. s. female : $63.3( \pm 10.8)$ years, $\mathrm{p}<0.01)$, and to care for younger frail elderly (male : $77.2( \pm 5.3)$ years v. s. female : $82.6( \pm 8.5)$ years, $\mathrm{p}=0.01)$ than female caregivers. Male caregivers were more likely to be a spouse (male : $15(75.0 \%)$ v. s. female : $20(39.2 \%), \mathrm{p}<0.01)$, female caregivers were more likely to be children (including "in-law") (male : $5(25.0 \%)$ v. s. female : $31 \quad(60.8 \%), \mathrm{p}<$ 0.01 ) than male caregivers. The number of male caregivers that cared for frail elderly males was zero, while on the other hand, the number of female caregivers was $31(60.8 \%)$. Nine $(45.0 \%)$ of the male and $20(39.2 \%)$ of the female caregivers were depressed. The rate of depressive caregivers did not differ between the two groups.

Table 2 demonstrates a comparison between male and female caregivers ; care setting. Male caregivers maintained their caregivers roles for longer periods than females with a longer duration of caregiving (mean $\pm \mathrm{SD}$; male : 68.1 (months) \pm 36.2 v. s. female $: 50.6$ (months) $\pm 48.8, \mathrm{p}=0.02$ ) than their counterparts. Male caregivers were more likely to have a daughter-in-law who helped from the outside $(p=0.03)$, and less likely to have a sister or brother who helped from the outside ( $p$ $<0.01)$ than female caregivers. Male caregivers were more likely to use home help service than their counterparts $(p<0.01)$. The number of male caregivers that used day a care service for the frail elderly was zero, and the number of females was 11 
Table 1 Comparison between male and female caregivers ; characteristics of caregivers and the frail elderly.

\begin{tabular}{lccc}
\hline & $\begin{array}{c}\text { Male caregivers } \\
(\mathrm{N}=20)\end{array}$ & $\begin{array}{c}\text { Female caregivers } \\
(\mathrm{N}=51)\end{array}$ & $\mathrm{p}$ \\
\hline Caregivers' characteristics & & & \\
Age (years old) & $71.7 \pm 11.6$ & $63.3 \pm 10.8$ & $<0.01$ \\
Caregivers who are spouses & $15(75.0 \%)$ & $20(39.2 \%)$ & $<0.01$ \\
Caregivers who are children & $5(25.0 \%)$ & $31(60.8 \%)$ & $<0.01$ \\
(including "-in-law") & & & \\
Consulting with own medical doctor & $12(60.0 \%)$ & $28(54.9 \%)$ & $=0.70$ \\
Felt ill (always, sometimes) & $8(40.0 \%)$ & $20(40.0 \%) \# \#$ & $=1.00$ \\
Had a job & $2(10.0 \%)$ & $8(15.7 \%)$ & $=0.54$ \\
Economic conditions (good, fair) & $8(40.0 \%)$ & $19(39.6 \%) \#$ & $=0.97$ \\
Depression & $9(45.0 \%)$ & $20(39.2 \%)$ & $=0.66$ \\
J-ZBI & $34.3 \pm 16.8$ & $33.7 \pm 18.1$ & $=0.79$ \\
Patients' characteristics & & & \\
Age (years old) & $77.2 \pm 5.3$ & $82.6 \pm 8.5$ & $=0.01$ \\
Gender (Male) & $0(0 \%)$ & $31(60.8 \%)$ & - \\
Barthel Index & $49.0 \pm 32.6$ & $61.2 \pm 31.6$ & $=0.14$ \\
Dementia & $13(65.0 \%)$ & $40(78.4 \%)$ & $=0.24$ \\
Dementia with behavioral disturbances* & $4(20.0 \%)$ & $9(17.6 \%)$ & $=0.82$ \\
\hline
\end{tabular}

* corresponding up to 1 item ; wandering or violence etc

Values are expressed as Mean \pm SD or number (\%)

$\# \mathrm{n}=48, \# \# \mathrm{n}=50$

$(21.6 \%)$.

In Table 3, the odds ratio and 95\% confidence intervals for male caregivers associated with related factors are shown. Male were more likely to use home-visit care (home help service) ( $\mathrm{OR}=$ $5.72,95 \% \mathrm{CI}=(1.75,18.68))$ than female caregivers, and male caregivers were less likely to care for the frail elderly who were older than 80 years old $(\mathrm{OR}=0.28,95 \% \mathrm{CI}=(0.08,0.994))$ even after adjusting for the caregivers' age.

\section{Discussion}

We conducted this study to assess for potential differences in caregiver gender and specific needs of the caregivers. We found that males were devoted caregivers, willing to care for a spouse for long durations of time. Males used home health support to assist them. After the patient age of 80, males were less likely to continue caregiving, perhaps because of their own age and health status.
We found that male caregivers were more likely to use a home help service than their female counterparts. The results of the present study are consistent with the results of the study by Sugiura et al. (2010), which showed that husband caregivers are more likely to use a home help service than wife caregivers in the baseline. These findings may be partly explained by the result of the study by Tsudome and Saito (2007), which demonstrated that male caregivers are less skilled at personal homemaking at home than females.

There are many male caregivers who may be in the situation of elder-to-elder nursing (Rourou Kaigo : in Japanese). Tsudome and Saito (2007) reports that the number and proportion of male caregivers is rapidly increasing. A comprehensive survey of living conditions of the people in Japan conducted by the Ministry of Health, Labour and Welfare (2008) reported that most people providing caregiving in Japan were born during the 1950's. 
Table 2 Comparison between male and female caregivers ; care setting

\begin{tabular}{|c|c|c|c|}
\hline & $\begin{array}{l}\text { Male caregivers } \\
\qquad(\mathrm{N}=20)\end{array}$ & $\begin{array}{l}\text { Female caregivers } \\
\qquad(\mathrm{N}=51)\end{array}$ & $\mathrm{p}$ \\
\hline $\begin{array}{l}\text { Time spent on physical caregiving } \\
\text { (hours/day) }\end{array}$ & $8.7 \pm 6.1$ & $7.9 \pm 6.6$ & $=0.34$ \\
\hline $\begin{array}{l}\text { Time attending the elderly } \\
\text { (hours/day) }\end{array}$ & $10.8 \pm 8.4$ & $8.3 \pm 7.2$ & $=0.28$ \\
\hline Duration of caregiving (months) & $68.1 \pm 36.2$ & $50.6 \pm 48.8$ & $=0.02$ \\
\hline Had a family member who helped with caregiving & $5(25 \%)$ & $23(45.1 \%)$ & $=0.12$ \\
\hline Had Help from the outside & $9(47.4 \%) \#$ & $26(51.0 \%)$ & $=0.79$ \\
\hline Daughter-in-law helped from the outside & $3(15.0 \%)$ & $1(2.0 \%)$ & $=0.03$ \\
\hline Sister or brother helped from the outside & $1(5.0 \%)$ & $18(35.3 \%)$ & $<0.01$ \\
\hline $\begin{array}{l}\text { Relieving irritated moods caused by caregiving } \\
\text { (possible) }\end{array}$ & $13(65.0 \%)$ & $39(78.0 \%) \# \# \# \# \#$ & $=0.26$ \\
\hline Use of a care service at home (well) & $17(85.0 \%)$ & $39(79.6 \%) \# \#$ & $=0.51$ \\
\hline Use of a care service at a facility (well) & $12(63.2 \%) \#$ & $25(54.3 \%) \# \# \#$ & $=0.51$ \\
\hline $\begin{array}{l}\text { Self payment of more than } 10,000 \text { Japanese Yen } \\
\text { as a part of total care service costs }\end{array}$ & $16(80.0 \%)$ & $27(55.1 \%) \# \#$ & $=0.053$ \\
\hline No. of times using public care service & $2.2 \pm 1.2$ & $2.0 \pm 1.1$ & $=0.38$ \\
\hline \multicolumn{4}{|l|}{ Used the following public service : } \\
\hline Home helper & $13(65.0 \%)$ & $12(23.5 \%)$ & $<0.01$ \\
\hline Bath services & $8(40.0 \%)$ & $16(31.4 \%)$ & $=0.49$ \\
\hline Day services & $8(40.0 \%)$ & $19(37.3 \%)$ & $=0.83$ \\
\hline Day care services & $0(0 \%)$ & $11(21.6 \%)$ & - \\
\hline Short stay services & $4(20.0 \%)$ & $10(19.6 \%)$ & $=0.97$ \\
\hline Food delivery services & $1(5.0 \%)$ & $4(7.8 \%)$ & $=0.67$ \\
\hline $\begin{array}{l}\text { Being able to go out without accompanying the } \\
\text { elderly }\end{array}$ & $15(75.0 \%)$ & $39(79.6 \%) \# \#$ & $=0.68$ \\
\hline
\end{tabular}

Values are expressed as Mean \pm SD or number (\%)

$\# \mathrm{n}=19, \# \# \mathrm{n}=49, \# \# \# \mathrm{n}=46, \# \# \# \# \mathrm{n}=20, \# \# \# \# \mathrm{n}=50$

Generally, many people of the 50's generation are still employed. Houde (2002) reported that success in caregiving was influenced by the relationship with the frail elderly, the generation, or the working situation in the case of male caregivers. An improved system to support of coexistence of athome care and outside employment will be needed in Japan. The use of home health nursing services can assist to fill that gap.

We recommend further studies on specific measures that support men's abilities to care for their spouses at home, as it appears that male caregivers are here to stay.

\section{Study Limitations}

The design of the present study was cross sectional and not, and therefore it was hard to understand the inter relationship between factors in terms of causes or effects. Second, this study is not geographically representative of all Japan. Third, the Odds Ratio was adjusted only for the caregivers' age because of the small number of subjects.

\section{Acknowledgements}

We would like to thank Professor Anita Catlin at Sonoma State University, and the nursing home's staff in Hokkaido General Home care Inc. Our 
Table 3 Odds ratio* and 95\% confidence intervals for male caregivers associated with related factors.

\begin{tabular}{|c|c|c|}
\hline & $\begin{array}{l}\text { Crude OR } \\
(95 \% \mathrm{CI})\end{array}$ & $\begin{array}{l}\text { Adjusted OR* } \\
\quad(95 \% \mathrm{CI})\end{array}$ \\
\hline \multicolumn{3}{|l|}{ Caregivers' characteristics } \\
\hline \multirow[t]{2}{*}{ Caregivers who are spouses } & 4.65 & 4.30 \\
\hline & $(1.46,14.80)$ & $(0.66,28.18)$ \\
\hline \multirow[t]{2}{*}{ Caregivers who are children } & 0.22 & 0.23 \\
\hline & $(0.07,0.68)$ & $(0.04,1.52)$ \\
\hline \multicolumn{3}{|l|}{ Patients' characteristics } \\
\hline \multirow[t]{2}{*}{ Age $(80+/ 79-)$} & 0.20 & 0.28 \\
\hline & $(0.07,0.63)$ & $(0.08,0.994)$ \\
\hline \multirow[t]{2}{*}{ Duration of caregiving $(48+/ 47-)$ (months) } & 2.28 & 1.83 \\
\hline & $(0.78,6.70)$ & $(0.60,5.61)$ \\
\hline \multicolumn{3}{|l|}{ Care setting } \\
\hline \multicolumn{3}{|l|}{ Had Help from the outside } \\
\hline \multirow[t]{2}{*}{ Daughter-in-law helped from the outside } & 8.82 & 6.27 \\
\hline & $(0.86,90.61)$ & $(0.58,67.40)$ \\
\hline \multirow[t]{2}{*}{ Sister or brother helped from the outside } & 0.10 & 0.14 \\
\hline & $(0.01,0.78)$ & $(0.02,1.28)$ \\
\hline \multicolumn{3}{|l|}{ Used the following public service : } \\
\hline \multirow[t]{2}{*}{ Home-visit care (Home help service) } & 6.04 & 5.72 \\
\hline & $(1.96,18.57)$ & $(1.75,18.68)$ \\
\hline Commuting for care (Day care) & -\# & -\# \\
\hline \multicolumn{3}{|l|}{ *Odds ratio : Adjusted “Caregiver's Age" } \\
\hline \multicolumn{3}{|l|}{$* * \mathrm{CI}:$ confidence interval } \\
\hline \# : measurement impossible & & \\
\hline
\end{tabular}

thanks go to the participants in the present study, which was in part supported by research grants provided by the Research Fellowships of the Japan Society for the Promotion of Science for Young Scientists (JSPS Research Fellowships for Young Scientists).

\section{References}

Arai Y, Sugiura M, Washio M, et al. (2001) Caregiver depression predicts early discontinuation of care for disabled elderly at home, Psychiat Clin Neurosci, 379, 379-382

Calasanti T and King N (2007) Taling Women's Work like a Man : Husbands experiences of care work, Gerontologist, 47, 516-527

Campbell JC (1992) How Policies Change: The Japanese Government and the Aging Society, Princeton University Press (New Jersey)

City of Sapporo (2011a) 5th Plan of health and the wel- fare for the elderly in Sapporo (in Japanese), http:// www.city.sapporo.jp/kaigo/k500plan/k552plan54kh. html, Retrieved July 6, 2011

City of Sapporo (2011b) When you thought about institution entering (in Japanese), http:/ / www.city. sapporo.jp/koreifukushi/index_3.html, Retrieved July 6, 2011

Farran CJ and Keane-Hagerty E (2011) Twelve Steps for Caregivers, http:/ /www.rush.edu/rumc/page ${ }^{-}$ R13418.html, Retrieved July 6, 2011

Houde SC (2002) Methodological issue in male caregiver research : an integrative review of the literature, J Adv Nurs, 40, 626-640

Kono S (2003) Demographic Aspects of Population Ageing in Japan, Japan Aging Research Center, Aging in Japan 2003, 7-51, Japan Aging Research Center (Tokyo)

Ministry of Health, Labour and Welfare (2008) Comprehensive Survey of Living Conditions of the People on Health and Welfare in 2008 (in Japanese), http:// www.mhlw.go.jp/toukei/saikin/hw/k-tyosa/k- 
tyosa07/4-3.html, Retrieved July 7, 2011

Ministry of Health, Labour and Welfare (2011) Health and Welfare Bureau for the elderly, http://www.mhlw. go.jp/english/policy/care-welfare/care-welfare-elderly/dl/long-term_care_health_and_walfare services_for_the_elderly.pdf, Retrieved Feb 4, 2013

Ministry of Internal Affairs and Communications, Statistics Bureau, Director-General for policy Planning \& Statistical Research and Training Institute (2011a) Chapter 2 population. Statistical Handbook in Japan 2011, http:/ /www.stat.go.jp/english/data/handbook/ c02cont.htm, Retrieved July 6, 2011

Ministry of Internal Affairs and Communications, Statistics Bureau, Director-General for policy Planning \& Statistical Research and Training Institute (2011b) Elderly of our country (in Japanese), http://www.stat. go.jp/data/topics/topi181.htm, Retrieved June 24, 2011

Oura A, Washio M, Arai Y, et al. (2007) Depression among caregivers of the frail elderly in Japan before and after the introduction of the public long-term care insurance system, Z Gerontol Geriat, 40, 112118
Radloff LS (1977) The CES-D scale : a self-report depression scale for research in the general population, Appl Psychol Meas, 1, 385-401

Sandberg J and Eriksson H (2007) The hard thing is the changes : the importance of continuity for older men caring for their wives, Qual Ageing, 8, 5-15

Shimizu Y (2003) Development of public long term care insurance and future direction of the elderly care, Japan Aging Research Center, Aging in Japan in 2003, 197-204, Aging Research Center (Tokyo)

Sugiura K, Ito M, Kutsumi M, et al. (2010) The causal relationship between caring experience and mental health state ; the case of spouse caregivers who caring the patients at home, Japanese Journal of Public Health, 57, 3-15 (in Japanese)

Tsudome M and Saito M (2007) White paper of male caregivers; proposal to the family caregivers support, Kamogawa (Kyoto) (in Japanese)

Washio M, Oura A, Arai Y, et al. (2003) Depression among caregivers of the frail elderly: three years after the introduction of public long-term care insurance for elderly, Int Med J, 10, 179-183

(Received 11. 12. 2011 ; Accepted 10. 3. 2012) 